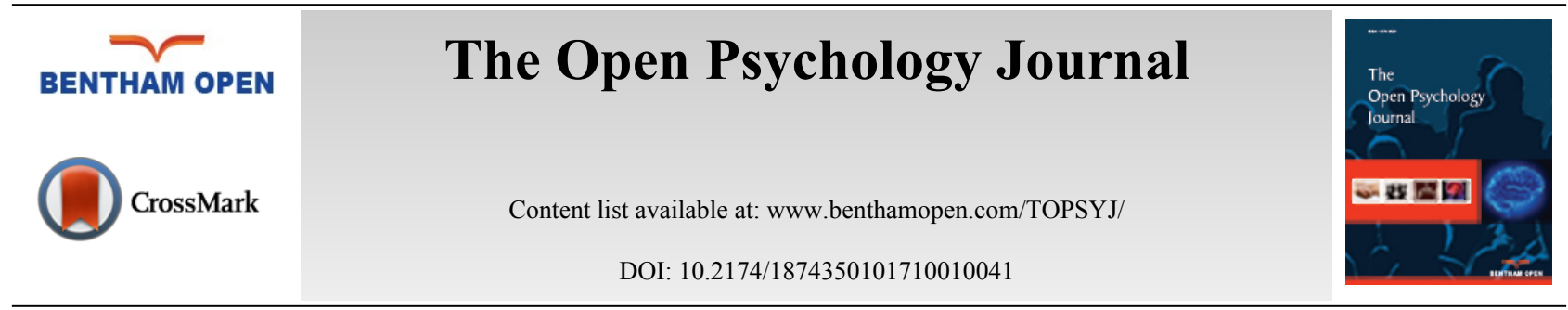

RESEARCH ARTICLE

\title{
Personality and Psychopathology in Patients with Systemic Sclerosis
}

\author{
Krisztina Csókási ${ }^{*}, 1$, Rita Hargitai ${ }^{2}$, Róbert Járai ${ }^{3}$, László Nagy ${ }^{1}$, László Czirják ${ }^{4}$ and Enikő C. Kiss ${ }^{1}$ \\ ${ }^{I}$ Department of Personality and Health Psychology, University of Pécs, Pécs, Hungary \\ ${ }^{2}$ Department of Personality and Clinical Psychology, Pázmány Péter Catholic University, Budapest, Hungary \\ ${ }^{3}$ Department of General and Evolutionary Psychology, University of Pécs, Pécs, Hungary \\ ${ }^{4}$ Department of Rheumatology and Immunology, University of Pécs, Pécs, Hungary
}

Received: October 29, 2016

Revised: January 20, 2017

Accepted: March 26, 2017

\begin{abstract}
:
Background:

Systemic sclerosis is an autoimmune connective tissue disease with significant pain, fatigue, and disability. Patients with systemic sclerosis are at increased risk for psychiatric disorders.
\end{abstract}

\section{Objective:}

This study assessed the personality and psychopathological characteristics of scleroderma patients.

\section{Method:}

Consecutive, in-patient female cases with systemic sclerosis $(\mathrm{N}=72)$ from the tertiary care center of the University of Pécs and ageand sex-matched healthy volunteers $(\mathrm{N}=56)$ and fifty patients with rheumatoid arthritis were enrolled. Participants completed the Minnesota Multiphasic Personality Inventory-2. Demographical and clinical data were also collected.

\section{Results:}

Rheumatoid arthritis and scleroderma patients had similar profiles with high scores ( $\geq 65 T)$ on Scales 1,2 and 3. Additionally, they achieved moderate scores on Scales 5 and 0 . The Scale 7 was elevated only in females with rheumatoid arthritis distinctively.

\section{Conclusion:}

High scores on Scales 1, 2 and 3 may reflect the severe somatic symptoms of systemic sclerosis (and rheumatoid arthritis), but may also refer to the disease-related emotional distress, anxiety and depression. Likewise, social withdrawal and less feminine interests may be the results of the chronic and disabling illness. The minor differences between the patient groups indicate that females with systemic sclerosis may be less vulnerable to specific anxiety disorders (obsessive-compulsive disorders, phobias). Study results highlight the importance of developing psychosocial interventions designed to meet the needs of scleroderma patients.

Keywords: Systemic sclerosis, Rheumatoid arthritis, Minnesota Multiphasic Personality Inventory-2 (MMPI-2), Depression, Anxiety, Hypochondriasis.

\section{INTRODUCTION}

Systemic sclerosis $(\mathrm{SSc})$ is a rare autoimmune connective tissue disease, with an estimated prevalence between 15 and 340 per 1 million persons [1]. Like other systemic autoimmune diseases, SSc is characterized by a multifactorial etiology, predominant female prevalence (female: male ratio is 9:1), progressive and unpredictable course of disease,

\footnotetext{
* Address correspondence to this author at Department of Personality and Health Psychology, University of Pécs, Pécs, Hungary Ifjúság str. 6, 7624 Pécs, Hungary Tel: 003672 503600; E-mail: csokasi.krisztina@pte.hu
} 
and diversity of clinical manifestations. Typical disease onset is between 30 and 50 years of age. Besides the autoimmune phenomena, central characteristics of SSc include vasculopathy and fibrosis of the skin and internal organs, which cause cold-induced Raynaud phenomenon and skin thickening. Furthermore, the disease may involve several inner organs, particularly the lungs, heart and kidneys, which may lead to poorer prognosis. Scleroderma patients often experience severe pain, fatigue, musculoskeletal disability and disfigurement.

In addition to physical symptoms, SSc patients are susceptible to psychological distress and internalizing psychiatric disorders. Prevalence estimates range between 36 percent and 65 percent for depression [2] and between 19 percent and 64 percent for anxiety [3,4], percentages which considerably exceed those of the general population. In a comparative study scleroderma patients reported even more depressive symptoms on the Beck Depression scale, than rheumatoid arthritis (RA) patients, although analysing the scores on cognitive-affective items separately, no statistical difference was found between RA and SSc patients [5]. The great variability in reported prevalence rates of depression and anxiety was attributed to methodological issues [2], because it may derive from comparisons of studies using different measurement methods, the overlap between symptoms of SSc and somatic symptoms of depression involved in certain questionnaires, and the different populations sampled (differences in age, gender, disease severity, etc.). Moreover, pathogenesis of anxiety and depression is also uncertain. They may be primary psychiatric conditions, or iatrogenicallyinduced illnesses (e.g. consequences of corticosteroid therapy), or emotional reactions to having a chronic and progressive disease. Studies assessing correlates of depression and anxiety have provided inconsistent results regarding gender, age, marital status, educational level, severity and subset (limited or diffuse SSc) of the disease and organ involvement. They have, however, an established relationship with pain [6,7], functional status $[5,8]$ and fatigue [6,9], because patients with worse functional status, or experiencing higher levels of pain or fatigue, tend to report more symptoms of anxiety and depression. Moreover, depression and anxiety are associated with impaired quality of life [5, $10]$.

Studies investigating the personality of SSc patients in relation to psychological adjustment have focused on certain aspects of personality. Scleroderma may cause changes in appearance, and skin deformities appear to be one of the strongest stressors in the life of patients [11]. SSc is associated with decreased appearance self-esteem, particularly in female patients, regardless of the objective extent of skin involvement and most coping styles [12]. Low appearance self-esteem and high body image dissatisfaction are related to psychological distress [12, 13]. Certain aspects of personality (e.g. sense of coherence and hostility) also appear to be linked to psychological distress [14]. Acceptance of the condition [12], use of humor as a coping strategy [15], relative optimism [11], empowering relationships, and valuing social support [6] may improve quality of life in SSc patients.

Previous studies have evaluated mainly the internalizing disorders and certain personality characteristics associated to SSc. The aim of this study was to explore the mental health of SSc patients taking into consideration the following viewpoints: (1) obtaining a complex psychopathological profile; (2) using a valid and wildly used clinical measurement method; and (3) comparing SSc patients to another patient group. Thus, in our study, we assessed the psychopathological characteristics of SSc patients using the Minnesota Multiphasic Personality Inventory-2 (MMPI-2). SSc patients were compared to healthy persons and patients with another inflammatory rheumatic disease, rheumatoid arthritis (RA). RA was used for comparison because it shares many similarities with SSc (e.g. chronicity, progressive disease course, and causing substantial burden on everyday life) and several previous studies have evaluated the psychological consequences of RA using the MMPI-2.

\section{MATERIAL AND METHODS}

\section{Procedure}

In this cross-sectional questionnaire-based study, consecutive patients were recruited from the Rheumatology and Immunology Department of the University of Pécs. We included RA and SSc in-patients undergoing their routine medical check-up in the clinic. Diseases were diagnosed according to the American College of Rheumatology (ACR) criteria [16, 17]. All of the enrolled patients met the following criteria: (1) RA or SSc diagnosis; (2) lack of overlap syndrome; (3) age $\geq 18$ years old; and (4) intact cognitive functioning evaluated with the Mini-Mental State Examination [18]. There were ninety-one SSc and sixty-eight RA patients that met these inclusion criteria, 18 of whom (7 with SSc and 11 with RA) refused participation.

Age- and sex-matched healthy volunteers were recruited from the community. Participants were contacted by undergraduate students of a Personality Psychology course. Students were offered extra course credits. The inclusion 
criteria for the control group were: (1) absence of any chronic disease; (2) age $\geq 18$ years old; and (3) intact cognitive functioning evaluated with the Mini-Mental State Examination. Sixty-five females met these criteria and agreed to participate in this study (information on refusal rate was not available).

After giving information about the aim of the study, written informed consent was obtained from all of the respondents. Participants did not receive any payment or compensation. The study was approved by the Regional Ethics Committee of the University of Pécs and was performed in accordance with the Helsinki declaration.

\section{Participants}

Fifty-seven female patients with RA and eighty-four with SSc completed the MMPI-2. We excluded five RA and six SSc patients from the analysis because of incomplete questionnaire data (omitting more than 30 items), and two RA and six SSc patients due to invalid profiles (defined by Infrequency scale (F) $>100$, Lie scale (L) $>80$, Correction scale (K) $>80$, True Response Inconsistency scale (TRIN) $>80$, Variable Response Inconsistency scale (VRIN) $>80$ ). Consequently, the final sample consisted of 50 females with RA and 72 females with SSc. Nine of the 65 healthy female volunteers were rejected because of incomplete data or invalid profiles, leaving 56 persons for the analysis.

Socio-demographics of the healthy and patient groups are presented in Table (1). There were no significant differences in age, years of education, and marital status across the three groups of subjects. The mean age was 55.36 $(\mathrm{SD}=11.04)$ years in the RA and $54.08(\mathrm{SD}=11.62)$ years in the $\mathrm{SSc}$ group, and $51.14(\mathrm{SD}=7.93)$ years in the healthy controls. The mean years of education was $11.92(\mathrm{SD}=2.46)$ for RA patients, $11.89(\mathrm{SD}=2.68)$ years for $\mathrm{SSc}$ patients, and $12.66(\mathrm{SD}=2.07)$ years for healthy females. The majority of participants (SSc: 70.8\%; RA: 64\%; healthy control: $78.6 \%$ ) were married.

Table 1. Demographics of healthy control group and patients with rheumatoid arthritis (RA) and systemic sclerosis (SSc).

\begin{tabular}{|c|c|c|c|c|}
\hline & $\begin{array}{l}\text { Healthy controls } \\
\qquad(n=56)\end{array}$ & $\begin{array}{c}\text { RA } \\
(n=50)\end{array}$ & $\begin{array}{c}\text { SSc } \\
(n=72)\end{array}$ & $\begin{array}{l}\text { F or } \chi^{2} \\
\text { p-value }\end{array}$ \\
\hline $\begin{array}{c}\text { Age (years) } \\
\text { Mean } \pm \text { SD } \\
95 \% \text { CI } \\
\text { Min-Max } \\
\end{array}$ & $\begin{array}{c}51.14 \pm 7.93 \\
49.02-53.27 \\
36-76\end{array}$ & $\begin{array}{c}55.36 \pm 11.04 \\
52.22-58.50 \\
26-73\end{array}$ & $\begin{array}{c}54.08 \pm 11.62 \\
51.35-56.81 \\
25-75\end{array}$ & $\begin{array}{c}\mathrm{F}=2.34 \\
\mathrm{NS}\end{array}$ \\
\hline $\begin{array}{l}\text { Education attendance (years) } \\
\text { Mean } \pm \text { SD } \\
95 \% \mathrm{CI} \\
\text { Min-Max }\end{array}$ & $\begin{array}{c}12.66 \pm 2.07 \\
12.11-13.22 \\
8-17\end{array}$ & $\begin{array}{c}11.92 \pm 2.46 \\
11.22-12.62 \\
8-17\end{array}$ & $\begin{array}{c}11.89 \pm 2.68 \\
11.26-12.52 \\
8-17\end{array}$ & $\begin{array}{c}\mathrm{F}=1.86 \\
\mathrm{NS}\end{array}$ \\
\hline $\begin{array}{c}\text { Marital status (n) } \\
\text { Single (\%) } \\
\text { Married (\%) }\end{array}$ & $\begin{array}{l}12(21.4 \%) \\
44(78.6 \%)\end{array}$ & $\begin{array}{l}18(36.0 \%) \\
32(64.0 \%)\end{array}$ & $\begin{array}{l}21(29.2 \%) \\
51(70.8 \%)\end{array}$ & $\begin{array}{c}\chi^{2}=2.76 \\
\mathrm{NS}\end{array}$ \\
\hline
\end{tabular}

$\mathrm{NS}=$ not significant $(\mathrm{p}>0.05) ; 95 \% \mathrm{CI}=$ confidence interval.

\section{Measures}

Participants completed a short socio-demographic form (asking age, gender, educational level, and marital status) and the MMPI-2 questionnaire.

Minnesota Multiphasic Personality Inventory-2 (MMPI-2): In this study, the validated Hungarian version of MMPI-2 was administered, which is a 567-item self-report measure of personality and psychopathology [19]. This revised form of the MMPI includes ten clinical scales (Hypochondriasis, Depression, Hysteria, Psychopathic Deviate, Masculinity-Femininity, Paranoia, Psychasthenia, Schizophrenia and Social introversion), 31 subscales, nine validity scales, 15 content scales, 15 supplementary scales, and five Personality Psychopathology scales. In this paper, only the validity and clinical scales and subscales are examined (analysis of subscales is reasonable if the score of the main scale is in the 'high' range). We used standardized scores based on the Hungarian normative data to interpret the MMPI-2 profiles. On each scale and subscale, T-scores between 45 and 57 were considered normal [20]. T-scores under 45 represented the 'low', and between 58 and 64 the 'moderate' range. T-scores $\geq 65$ were considered 'high' that may indicate clinically significant problems or dysfunction.

\section{Statistical Methods}

Differences in demographics among the three groups were assessed with Pearson's chi-square test and one-way analyses of variance (ANOVA) for discrete and continuous variables, respectively. One-way ANOVA with Bonferroni 
post hoc test and Student's t test were used to compare the mean scores of SSc and RA patients and healthy subjects on MMPI-2 scales and subscales. Differences in the proportion of patients scoring above 65T were analyzed by Pearson's chi-square test or Fisher's exact test when the observed frequencies were small. A value of $p \leq 0.05$ was considered statistically significant. All statistical analyses were conducted using SPSS version 19.

\section{RESULTS}

Mean scores of healthy participants and SSc and RA patients on MMPI-2 clinical scales are shown in Table (2). RA and SSc patients reached significantly higher scores compared to healthy participants on the Scale $1(\mathrm{~F}(2,175)=37.59$; $\mathrm{p}<0.001)$, Scale $2(\mathrm{~F}(2,175)=35.70 ; \mathrm{p}<0.001)$, and Scale $3(\mathrm{~F}(2,175)=38.73 ; \mathrm{p}<0.001)$. The patient groups scored in the high range (above 65T) on the neurotic triad (Scales 1, 2, 3). Both patient groups presented moderate scores on the Scales 5 and 0 . The Scale 7 was moderately elevated only in females with rheumatoid arthritis distinctively. Means on the Scales 4, 6, 8 and 9 were within the normal range in all three groups.

As shown in Table (2), the majority of females with RA and SSc scored in the clinically elevated range on the Scale 1 (62\% and $63.9 \%$ respectively), Scale 2 (64\% and $66.7 \%)$, and Scale $3(58 \%$ and $52.8 \%)$. Approximately one third of SSc (30.6\%) and RA (34\%) patients had high scores on the Scale 0. However, only a few of them presented high scores on the Scales 4, 6 and 9. Statistical differences between groups were found on the Scales 7 and 5. Significantly fewer SSc patients produced high scores on the Scale $7\left(19.4 \%\right.$ vs. $\left.36 \% ; \chi^{2}(1)=4.18 ; p=0.041\right)$ and marginally more sclerodermic patients had high scores on the Scale $5\left(41.7 \%\right.$ vs. $\left.26 \% ; \chi^{2}(1)=3.17 ; \mathrm{p}=0.075\right)$.

Table 2. Mean T-scores on MMPI-2 clinical scales of healthy subjects and rheumatoid arthritis (RA) and systemic sclerosis (SSc) patients and the rates of patients scoring above $65 \mathrm{~T}$.

\begin{tabular}{|c|c|c|c|c|c|c|c|c|}
\hline MMPI-2 clinical scales & $\begin{array}{c}\text { Healthy } \\
(\mathrm{n}=56) \\
\mathrm{M} \\
\text { (SD) }\end{array}$ & $\begin{array}{c}\text { RA } \\
(\mathbf{n}=\mathbf{5 0}) \\
\mathbf{M}(\mathrm{SD})\end{array}$ & $\begin{array}{c}\text { SSc } \\
(\mathrm{n}=72) \\
\mathrm{M}(\mathrm{SD})\end{array}$ & & $\begin{array}{l}\text { NOVA } \\
\text { F p }\end{array}$ & $\begin{array}{c}\geq 65 T \text { in RA group } \\
n(\%)\end{array}$ & $\begin{array}{c}\geq 65 T \text { in } S S c \text { group } \\
n(\%)\end{array}$ & $\begin{array}{c}\chi^{2} \\
\text { p-value }\end{array}$ \\
\hline Hypochondriasis (Hs) & $\begin{array}{c}52.89 \\
(10.68)\end{array}$ & $\begin{array}{c}67.43 \\
(10.46)\end{array}$ & $\begin{array}{c}68.29 \\
(11.04)\end{array}$ & 37.59 & $\mathrm{p}<0.001^{\mathrm{a}, \mathrm{b}}$ & $\begin{array}{c}31 \\
(62.0 \%)\end{array}$ & $\begin{array}{c}46 \\
(63.9 \%)\end{array}$ & $\begin{array}{l}0.05 \\
\mathrm{NS}\end{array}$ \\
\hline Depression (D) & $\begin{array}{c}52.64 \\
(11.53)\end{array}$ & \begin{tabular}{|c|}
68.76 \\
$(11.97)$
\end{tabular} & \begin{tabular}{|c|}
67.82 \\
$(10.95)$
\end{tabular} & 35.70 & $\mathrm{p}<0.001^{\mathrm{a}, \mathrm{b}}$ & $\begin{array}{c}32 \\
(64.0 \%)\end{array}$ & $\begin{array}{c}48 \\
(66.7 \%)\end{array}$ & $\begin{array}{l}0.09 \\
\text { NS }\end{array}$ \\
\hline Hysteria (Hy) & $\begin{array}{c}50.13 \\
(10.80) \\
\end{array}$ & $\begin{array}{c}65.60 \\
(10.16)\end{array}$ & $\begin{array}{c}65.48 \\
(11.32)\end{array}$ & 38.73 & $\mathrm{p}<0.001^{\mathrm{a}, \mathrm{b}}$ & $\begin{array}{c}29 \\
(58.0 \%)\end{array}$ & $\begin{array}{c}38 \\
(52.8 \%)\end{array}$ & $\begin{array}{l}0.33 \\
\mathrm{NS}\end{array}$ \\
\hline Psychopathic Deviate (Pd) & $\begin{array}{l}46.72 \\
(7.56)\end{array}$ & $\begin{array}{c}48.79 \\
(10.14)\end{array}$ & $\begin{array}{l}49.90 \\
(9.15)\end{array}$ & 1.99 & NS & $\begin{array}{c}4 \\
(8.0 \%)\end{array}$ & $\begin{array}{c}4 \\
(5.6 \%)\end{array}$ & $\begin{array}{l}0.29 \\
\mathrm{NS}\end{array}$ \\
\hline Masculinity-Femininity (Mf) & $\begin{array}{l}56.18 \\
(5.10)\end{array}$ & $\begin{array}{l}60.14 \\
(6.68)\end{array}$ & $\begin{array}{l}62.13 \\
(6.81)\end{array}$ & 14.31 & $\mathrm{p}<0.001^{\mathrm{a}, \mathrm{b}}$ & $\begin{array}{c}13 \\
(26.0 \%)\end{array}$ & $\begin{array}{c}30 \\
(41.7 \%)\end{array}$ & \begin{tabular}{|c|}
3.17 \\
$\mathrm{p}=0.075$
\end{tabular} \\
\hline Paranoia (Pa) & $\begin{array}{c}48.59 \\
(10.57) \\
\end{array}$ & $\begin{array}{l}53.69 \\
(8.91)\end{array}$ & $\begin{array}{l}49.63 \\
(9.03)\end{array}$ & 4.24 & $\mathrm{p}<0.05^{\mathrm{a}}$ & $\begin{array}{c}7 \\
(14.0 \%)\end{array}$ & $\begin{array}{c}6 \\
(8.3 \%)\end{array}$ & $\begin{array}{l}0.99 \\
\mathrm{NS}\end{array}$ \\
\hline Psychasthenia (Pt) & $\begin{array}{l}48.97 \\
(9.74)\end{array}$ & \begin{tabular}{|c|}
58.89 \\
$(10.94)$
\end{tabular} & \begin{tabular}{|c|}
56.54 \\
$(10.27)$ \\
\end{tabular} & 13.96 & $\mathrm{p}<0.001^{\mathrm{a}, \mathrm{b}}$ & $\begin{array}{c}18 \\
(36.0 \%)\end{array}$ & $\begin{array}{c}14 \\
(19.4 \%)\end{array}$ & $\begin{array}{c}4.18 \\
p=0.041\end{array}$ \\
\hline Schizophrenia (Sc) & $\begin{array}{l}48.21 \\
(8.57)\end{array}$ & \begin{tabular}{|c|}
56.38 \\
$(10.78)$
\end{tabular} & \begin{tabular}{|l|}
54.55 \\
$(9.38)$ \\
\end{tabular} & 11.10 & $\mathrm{p}<0.001^{\mathrm{a}, \mathrm{b}}$ & $\begin{array}{c}11 \\
(22.0 \%)\end{array}$ & $\begin{array}{c}11 \\
(15.3 \%)\end{array}$ & $\begin{array}{l}0.90 \\
\text { NS }\end{array}$ \\
\hline Hypomania (Ma) & $\begin{array}{l}46.39 \\
(9.99) \\
\end{array}$ & $\begin{array}{l}45.92 \\
(8.99) \\
\end{array}$ & $\begin{array}{l}46.29 \\
(9.80)\end{array}$ & 0.04 & NS & $\begin{array}{c}1 \\
(2.0 \%) \\
\end{array}$ & $\begin{array}{c}3 \\
(4.2 \%) \\
\end{array}$ & $\begin{array}{l}0.44 \\
\text { NS }\end{array}$ \\
\hline Social Introversion (Si) & $\begin{array}{c}51.62 \\
(10.64)\end{array}$ & $\begin{array}{l}59.83 \\
(9.49)\end{array}$ & $\begin{array}{l}58.17 \\
(9.38)\end{array}$ & 10.82 & $\mathrm{p}<0.001^{\mathrm{a}, \mathrm{b}}$ & $\begin{array}{c}17 \\
(34.0 \%)\end{array}$ & $\begin{array}{c}22 \\
(30.6 \%)\end{array}$ & $\begin{array}{l}0.16 \\
\mathrm{NS}\end{array}$ \\
\hline
\end{tabular}

$\mathrm{NS}=$ not significant $(\mathrm{p}>0.05)$; $\mathrm{a}=$ significant difference: healthy $v s$. RA (Bonferroni post hoc); $\mathrm{b}=$ significant difference: healthy $v s$. SSc (Bonferroni post hoc).

Examination of subscales was reasonable for the Scales 2 and 3 Table (3) in patient groups (scores on the Scale 1 were also elevated, but it has no subscales). Regarding the five subscales of Scale 2, high scores were found on Physical Malfunctioning in both patient groups. Mean scores on Subjective Depression and Mental Dullness were mildly elevated, whilst scores on Brooding and Psychomotor Retardation subscales were in the normal range in both groups. Statistical analysis revealed no significant differences between RA and SSc patients in any of the subscales. Exploring the pattern of the subscales of Scale 3, we found high scores on Somatic Complaints and moderate scores on LassitudeMalaise in both patient groups. SSc and RA patients had normal or low scores on the other subscales. However, there was a statistically significant (but not clinically meaningful) difference between them with respect to Denial of Social Anxiety, because RA patients scored even lower $(\mathrm{t}(120)=-2.03 ; \mathrm{p}=0.045)$ than SSc patients. 
We also examined the proportion of patients scoring in the high range on these subscales (Table 3). Most of the RA and SSc patients (74\% and 77.8\%, respectively) scored above 65T on Physical Malfunctioning. More than half of the RA group and nearly half of the SSc group had high scores on Lassitude-Malaise (60\% vs. 45.8\%) and Somatic Complaints (62\% vs. 52.8\%). Relatively high frequencies were found on Subjective Depression, because 40 percent of RA patients and 37.5 percent of SSc patients scored in the high range. High scores on Psychomotor Retardation and Mental Dullness were less common (20.8 - 27.8\%). Scores above 65T on Brooding, Need for Affection, and Inhibition of Aggression were even rarer (9.7 - 18\%) in RA and SSc patients. We found no significant differences in the distribution of patients scoring above $65 \mathrm{~T}$ or in the normal range between SSc and RA patients on any of the subscales.

Table 3. Mean T-scores on subscales of Depression and Hysteria of rheumatoid arthritis (RA) and systemic sclerosis (SSc) patients and the rates of patients scoring above $65 \mathrm{~T}$.

\begin{tabular}{|c|c|c|c|c|c|c|}
\hline Subscales of Depression and Hysteria & $\begin{array}{c}\mathbf{R A} \\
(\mathrm{n}=\mathbf{5 0}) \\
\mathrm{M} \pm \mathbf{S D}\end{array}$ & $\begin{array}{c}\text { SSc } \\
(n=72) \\
M \pm S D\end{array}$ & $\begin{array}{c}\text { t } \\
\text { p-value }\end{array}$ & $\begin{array}{c}\geq 65 \mathrm{~T} \text { in } \mathrm{RA} \text { group } \\
\mathrm{n}(\%)\end{array}$ & $\begin{array}{c}\geq 65 \mathrm{~T} \text { in SSc group } \\
\mathrm{n}(\%)\end{array}$ & $\begin{array}{c}\chi^{2} \\
\text { p-value }\end{array}$ \\
\hline \multicolumn{7}{|l|}{ Depression (D) } \\
\hline Subjective Depression (D1) & $62.07 \pm 11.43$ & $60.17 \pm 10.74$ & $\begin{array}{l}0.94 \\
\text { NS }\end{array}$ & $\begin{array}{c}20 \\
(40.0 \%)\end{array}$ & $\begin{array}{c}27 \\
(37.5 \%)\end{array}$ & $\begin{array}{l}0.08 \\
\mathrm{NS}\end{array}$ \\
\hline Psychomotor Retardation (D2) & $57.34 \pm 10.79$ & $57.40 \pm 9.95$ & $\begin{array}{c}-0.03 \\
\mathrm{NS}\end{array}$ & $\begin{array}{c}11 \\
(22.0 \%)\end{array}$ & $\begin{array}{c}15 \\
(20.8 \%)\end{array}$ & $\begin{array}{l}0.02 \\
\mathrm{NS}\end{array}$ \\
\hline Physical Malfunctioning (D3) & $68.39 \pm 10.52$ & $68.91 \pm 10.78$ & $\begin{array}{c}-0.26 \\
\mathrm{NS}\end{array}$ & $\begin{array}{c}37 \\
(74.0 \%)\end{array}$ & $\begin{array}{c}56 \\
(77.8 \%) \\
\end{array}$ & $\begin{array}{l}0.23 \\
\mathrm{NS}\end{array}$ \\
\hline Mental Dullness (D4) & $57.77 \pm 10.39$ & $58.23 \pm 10.98$ & $\begin{array}{c}-0.23 \\
\mathrm{NS}\end{array}$ & $\begin{array}{c}13 \\
(26.0 \%) \\
\end{array}$ & $\begin{array}{c}20 \\
(27.8 \%)\end{array}$ & $\begin{array}{l}0.05 \\
\mathrm{NS}\end{array}$ \\
\hline Brooding (D5) & $55.67 \pm 7.86$ & $53.55 \pm 8.71$ & $\begin{array}{l}1.38 \\
\mathrm{NS}\end{array}$ & $\begin{array}{c}7 \\
(14.0 \%) \\
\end{array}$ & $\begin{array}{c}8 \\
(11.1 \%) \\
\end{array}$ & $\begin{array}{l}0.23 \\
\mathrm{NS}\end{array}$ \\
\hline \multicolumn{7}{|l|}{ Hysteria (Hy) } \\
\hline Denial of Social Anxiety (Hy1) & $43.66 \pm 9.73$ & $47.21 \pm 9.39$ & $\begin{array}{c}-2.03 \\
\mathrm{p}<0.05\end{array}$ & $\begin{array}{c}- \\
(0 \%)\end{array}$ & $\begin{array}{c}- \\
(0 \%)\end{array}$ & \\
\hline Need for Affection (Hy2) & $47.79 \pm 10.19$ & $48.96 \pm 11.17$ & $\begin{array}{c}-0.59 \\
\mathrm{NS}\end{array}$ & $\begin{array}{c}6 \\
(12.0 \%) \\
\end{array}$ & $\begin{array}{c}7 \\
(9.7 \%) \\
\end{array}$ & $\begin{array}{l}0.16 \\
\mathrm{NS}\end{array}$ \\
\hline Lassitude-Malaise (Hy3) & $64.48 \pm 8.70$ & $63.12 \pm 8.55$ & $\begin{array}{l}0.86 \\
\mathrm{NS}\end{array}$ & $\begin{array}{c}30 \\
(60.0 \%)\end{array}$ & $\begin{array}{c}33 \\
(45.8 \%) \\
\end{array}$ & $\begin{array}{l}2.37 \\
\mathrm{NS}\end{array}$ \\
\hline Somatic Complaints (Hy4) & $67.40 \pm 11.21$ & $65.66 \pm 11.23$ & $\begin{array}{l}0.84 \\
\mathrm{NS}\end{array}$ & $\begin{array}{c}31 \\
(62.0 \%)\end{array}$ & $\begin{array}{c}38 \\
(52.8 \%)\end{array}$ & $\begin{array}{l}1.02 \\
\mathrm{NS}\end{array}$ \\
\hline Inhibition of Aggression (Hy5) & $52.05 \pm 11.27$ & $51.72 \pm 11.43$ & $\begin{array}{l}0.16 \\
\mathrm{NS}\end{array}$ & $\begin{array}{c}9 \\
(18.0 \%)\end{array}$ & $\begin{array}{c}9 \\
(12.5 \%)\end{array}$ & $\begin{array}{c}0.71 \\
\mathrm{NS}\end{array}$ \\
\hline
\end{tabular}

$\mathrm{NS}=$ not significant $(\mathrm{p}>0.05)$.

\section{DISCUSSION}

Using the MMPI-2 questionnaire, this is the first study exploring the personality and psychopathological characteristics of SSc patients in comparison with RA patients and healthy volunteers. RA and SSc patients considerably differed from healthy controls in their clinical personality profiles, but were only slightly different from each other. The salient features of the patient profiles were the high scores (at or above 65T) of the Scales 1, 2 and 3. Moderate scores were presented on the Scales 5 and 0 by both groups and on the Scale 7 by the RA group.

These characteristics of the profiles imply that females with RA and SSc have a strong tendency to worry about their health, to be engaged in their bodily processes intensely and to focus their attention to them regularly (high Scale 1 scores). Additionally, they reported poor health status, high levels of fatigue and weakness, and many specific somatic symptoms (high scores on Physical Malfunctioning, Lassitude-Malaise, and Somatic Complaints). Furthermore, RA and SSc patients seemed to feel anxiety, tension, or unhappiness often, and had doubts about their abilities and skills, which may lead to a lack of self-confidence and feelings of inferiority (high scores on Scale 2 and moderate scores on Scale 0 ). Moderate scores on the Subjective Depression and Scale 0 indicate that they are frequently uninterested in what goes on around them and in social situations they are shy and embarrassed. Besides, they can be characterized by less feminine attitude, interest and emotional reactions (moderate scores on Scale 5).

The explored profiles of RA and SSc patients are consistent with the results of prior studies. Elevations on the neurotic triad (Scale 1, 2 and 3) have been reinforced several times in RA samples [21 - 24]. Others reported clinically elevated scores (between 62 and 68T) on the Scales 1, 2 and 3 and normal or moderate scores on the other scales. 
Moreover, comparable profiles have been identified in other chronically ill populations, such as patients with chronic obstructive pulmonary disease [25], fibromyalgia and chronic pain [26], and systemic lupus erythematosus [21, 27, 28]. We may therefore suppose that the characteristics of the MMPI-2 profile in SSc (and RA) patients reflect the consequences of the 'sick role'. That is, our results probably indicate the impact of the chronic, painful and disabling disease that may give rise to emotional distress (high scores on the neurotic triad scales) and difficulties in contacting with persons (moderate scores on the Scale 0). However, pre-existing depression, emotional distress and greater social isolation may have altered the course of the disease and treatment.

High scores on the neurotic triad scales confirm the susceptibility of SSc patients to psychological distress and high prevalence rates of depression and anxiety reported previously [2, 3]. However, our results revealed that elevated scores of the neurotic triad scales were obtained primarily due to the many physical symptoms (elevated scores on the Physical Malfunctioning, Lassitude-Malaise and Somatic Complaints subscales) experienced by the patients. These symptoms may reflect either the multisystem clinical manifestations of SSc (resulting in 'artificially' elevated scores) or the somatic signs of emotional distress; anyhow, these physical complaints may impair the quality of life of patients [29]. Nevertheless, elevated scores on the Subjective Depression subscale in 37.5 percent of SSc patients suggest that they are indeed at great risk for depression.

Only small differences were found in response patterns between SSc and RA patients. RA patients scored in the moderate range on the Scale 7, which reflects their strong tendency to experience tension, anxiety, self-doubt, unreasonable fear and worrying. Moreover, significantly fewer patients with SSc than with RA (19.4\% vs. 36\%) reported symptoms in the high range (at or above $65 \mathrm{~T}$ score) on this scale. This may propose that patients with SSc are less disturbed by psychological distress in terms of anxiety and obsessive worrying, but further studies are needed to confirm whether anxiety disorders are less prevalent in patients with SSc than with RA. On the other hand, somewhat more patients with SSc than with RA (41.7\% vs. 26\%) reported that they were less interested in feminine activities, vocations or hobbies, which may be related to the characteristics of the disease, namely socially relevant disfigurement (e.g. skin thickening on face and hands, and deformity of the hands) leading to body image dissatisfaction [12], or urogenital tract involvement. In addition, our finding is in line with former reports on impaired sexual functioning in females with SSc [30] - however, Scale 5 is an interest scale and does not indicate clinically significant problems or dysfunction.

Although this study has some limitations, such as the size and the gender composition of the sample and the exclusion of the content and supplementary scales from the analysis, our data suggest that the MMPI-2 can provide clinically useful information about the psychological status of SSc patients. Nevertheless, future studies are needed to develop disease-specific scales from the items of the MMPI-2. Additionally, studies aimed at exploring the interrelation between the MMPI-2 personality profiles and the objective medical indices (disability, duration, type of treatment, etc.) are also required.

\section{CONCLUSION}

In conclusion, high scores on the neurotic triad scales (Scales 1, 2, 3), and moderate scores on the Scales 5 and 0 were found in patients with SSc, reflecting the psychosocial impact of the disease. Female SSc patients reported many somatic symptoms such as fatigue and malaise, and psychological symptoms such as emotional distress, depression, low self-esteem, and uncertainty. Moreover, our results suggest that the majority of them may also experience a decline in their social lives. Interventions targeted at treating and/or preventing anxiety and depression and promoting adaptive coping mechanisms may have clinical benefits in this population. Psychosocial interventions that may improve social engagement and decrease social and role limitations should be integrated into interdisciplinary care.

\section{ETHICS APPROVAL AND CONSENT TO PARTICIPATE}

The study was approved by the Regional Ethics Committee of the University of Pécs and was performed according to the Helsinki declaration.

\section{HUMAN AND ANIMAL RIGHTS}

No Animals/Humans were used for studies that are base of this research.

\section{CONSENT FOR PUBLICATION}

Not applicable. 


\section{CONFLICT OF INTEREST}

The author confirms that this article content has no conflict of interest.

\section{ACKNOWLEDGEMENTS}

This research was supported by the Hungarian Scientific Research Fund (OTKA) under Grant numbers K71754 and K112939. The project has been supported by the European Union, co-financed by the European Social Fund (EFOP-3.6.1.-16-2016-00004).

\section{REFERENCES}

[1] Denton CP, Moinzadeh P. Systemic sclerosis. In: Watts RA, Conaghan PG, Denton C, Foster H, Isaacs J, Müller-Ladner U, Eds. Oxford Textbook of Rheumatology. 4th ed. Oxford: Oxford University Press 2013; pp. 971-88. [http://dx.doi.org/10.1093/med/9780199642489.003.0121]

[2] Thombs BD, Taillefer SS, Hudson M, Baron M. Depression in patients with systemic sclerosis: a systematic review of the evidence. Arthritis Rheum 2007; 57(6): 1089-97. [http://dx.doi.org/10.1002/art.22910] [PMID: 17665491]

[3] Baubet T, Ranque B, Taïeb O, et al. Mood and anxiety disorders in systemic sclerosis patients. Presse Med 2011; 40(2): e111-9. [http://dx.doi.org/10.1016/j.lpm.2010.09.019] [PMID: 21055901]

[4] Legendre C, Allanore Y, Ferrand I, Kahan A. Evaluation of depression and anxiety in patients with systemic sclerosis. Joint Bone Spine 2005; 72(5): 408-11

[http://dx.doi.org/10.1016/j.jbspin.2003.11.008] [PMID: 16214073]

[5] Danieli E, Airò P, Bettoni L, et al. Health-related quality of life measured by the Short Form 36 (SF-36) in systemic sclerosis: correlations with indexes of disease activity and severity, disability, and depressive symptoms. Clin Rheumatol 2005; 24(1): 48-54. [http://dx.doi.org/10.1007/s10067-004-0970-z] [PMID: 15300468]

[6] Kwakkenbos L, van Lankveld WG, Vonk MC, Becker ES, van den Hoogen FH, van den Ende CH. Disease-related and psychosocial factors associated with depressive symptoms in patients with systemic sclerosis, including fear of progression and appearance self-esteem. $\mathrm{J}$ Psychosom Res 2012; 72(3): 199-204

[http://dx.doi.org/10.1016/j.jpsychores.2011.12.005] [PMID: 22325699]

[7] Schieir O, Thombs BD, Hudson M, et al. Prevalence, severity, and clinical correlates of pain in patients with systemic sclerosis. Arthritis Care Res (Hoboken) 2010; 62(3): 409-17. [http://dx.doi.org/10.1002/acr.20108] [PMID: 20391488]

[8] Nietert PJ, Mitchell HC, Bolster MB, Curran MY, Tilley BC, Silver RM. Correlates of depression, including overall and gastrointestinal functional status, among patients with systemic sclerosis. J Rheumatol 2005; 32(1): 51-7. [PMID: 15630725]

[9] Thombs BD, Hudson M, Bassel M, Taillefer SS, Baron M. Sociodemographic, disease, and symptom correlates of fatigue in systemic sclerosis: evidence from a sample of 659 Canadian Scleroderma Research Group Registry patients. Arthritis Rheum 2009; 61(7): 966-73. [http://dx.doi.org/10.1002/art.24614] [PMID: 19565539]

[10] Rannou F, Poiraudeau S, Berezné A, et al. Assessing disability and quality of life in systemic sclerosis: Construct validities of the Cochin hand function scale, health assessment questionnaire (HAQ), systemic sclerosis HAQ, and medical outcomes study $36 \square$ item short form health survey. Arthritis Rheum 2007; 57(1): 94-102. [http://dx.doi.org/10.1002/art.22468] [PMID: 17266096]

[11] Nakayama A, Tunnicliffe DJ, Thakkar V, et al. Patients perspectives and experiences living with systemic sclerosis: A systematic review and thematic synthesis of qualitative studies. J Rheumatol 2016; 43(7): 1363-75. [http://dx.doi.org/10.3899/jrheum.151309] [PMID: 27134259]

[12] van Lankveld WG, Vonk MC, Teunissen H, van den Hoogen FH. Appearance self-esteem in systemic sclerosissubjective experience of skin deformity and its relationship with physician-assessed skin involvement, disease status and psychological variables. Rheumatology (Oxford) 2007; 46(5): 872-6.

[http://dx.doi.org/10.1093/rheumatology/kem008] [PMID: 17308314]

[13] Benrud-Larson LM, Heinberg LJ, Boling C, et al. Body image dissatisfaction among women with scleroderma: extent and relationship to psychosocial function. Health Psychol 2003; 22(2): 130-9. [http://dx.doi.org/10.1037/0278-6133.22.2.130] [PMID: 12683733]

[14] Hyphantis TN, Tsifetaki N, Pappa C, et al. Clinical features and personality traits associated with psychological distress in systemic sclerosis patients. J Psychosom Res 2007; 62(1): 47-56.

[http://dx.doi.org/10.1016/j.jpsychores.2006.07.028] [PMID: 17188120]

[15] Merz EL, Malcarne VL, Hansdottir I, Furst DE, Clements PJ, Weisman MH. A longitudinal analysis of humor coping and quality of life in systemic sclerosis. Psychol Health Med 2009; 14(5): 553-66. [http://dx.doi.org/10.1080/13548500903111798] [PMID: 19844834] 
[16] Aletaha D, Neogi T, Silman AJ, et al. 2010 Rheumatoid arthritis classification criteria: an American College of Rheumatology/European League Against Rheumatism collaborative initiative. Arthritis Rheum 2010; 62(9): 2569-81. [http://dx.doi.org/10.1002/art.27584] [PMID: 20872595]

[17] van den Hoogen F, Khanna D, Fransen J, et al. 2013 classification criteria for systemic sclerosis: an American College of Rheumatology/European League against Rheumatism collaborative initiative. Arthritis Rheum 2013; 65(11): $2737-47$. [http://dx.doi.org/10.1002/art.38098] [PMID: 24122180]

[18] Folstein MF, Folstein SE, McHugh PR. Mini-mental state. A practical method for grading the cognitive state of patients for the clinician. J Psychiatr Res 1975; 12(3): 189-98.

[http://dx.doi.org/10.1016/0022-3956(75)90026-6] [PMID: 1202204]

[19] Butcher JN, Dahlstrom WG, Graham JR, Tellegen AM, Kaemmer B. Minnesota Multiphasic Personality Inventory-2 (MMPI-2): Manual for administration and scoring. MMPI-2, Minnesota Multiphasic Personality Inventory-2. Kézikönyv. Budapest: OS Hungary 2009

[20] Greene RL. The MMPI-2: An interpretive manual. 2nd ed. Boston: Allyn and Bacon 2000.

[21] Liang MH, Rogers M, Larson M, et al. The psychosocial impact of systemic lupus erythematosus and rheumatoid arthritis. Arthritis Rheum 1984; 27(1): 13-9. [http://dx.doi.org/10.1002/art.1780270102] [PMID: 6691857]

[22] Moos RH, Solomon GF. Minnesota Multiphasic Personality Inventory response patterns in patients with rheumatoid arthritis. J Psychosom Res 1964; 8(1): 17-28.

[http://dx.doi.org/10.1016/0022-3999(64)90018-2] [PMID: 14181652]

[23] Pincus T, Callahan LF, Bradley LA, Vaughn WK, Wolfe F. Elevated MMPI scores for hypochondriasis, depression, and hysteria in patients with rheumatoid arthritis reflect disease rather than psychological status. Arthritis Rheum 1986; 29(12): 1456-66. [http://dx.doi.org/10.1002/art.1780291206] [PMID: 3801070]

[24] Wolfe F, Cathey MA, Kleinheksel SM, et al. Psychological status in primary fibrositis and fibrositis associated with rheumatoid arthritis. J Rheumatol 1984; 11(4): 500-6. [PMID: 6592358]

[25] Zhukava T, Shot I. Psychological features and emotional frustrations of chronic obstructive pulmonary diseases and asthma patients. Pol Ann Med 2012; 19(2): 94-7.

[http://dx.doi.org/10.1016/j.poamed.2012.08.002]

[26] Pérez-Pareja J, Sesé A, González-Ordi H, Palmer A. Fibromyalgia and chronic pain: Are there discriminating patterns by using the Minnesota Multiphasic Personality Inventory-2 (MMPI-2)? Int J Clin Health Psychol 2010; 10(1): 41-56.

[27] Csókási K, Hargitai R, Járai R, Nagy L, Czirják L, Kiss EC. [MMPI-2 profiles in groups of systemic autoimmune disease - rheumatoid arthritis and systemic lupus erythematosus - patients]. Psychiatr Hung 2015; 30(4): 409-17. MMPI-2 profiles in groups of systemic autoimmune disease-rheumatoid arthritis and systemic lupus erythematosus-patients. [PMID: 26771700]

[28] Waterloo K, Omdal R, Husby G, Mellgren SI. Emotional status in systemic lupus erythematosus. Scand J Rheumatol 1998; $27(6)$ : 410-4. [http://dx.doi.org/10.1080/030097498442226] [PMID: 9855210]

[29] Suarez-Almazor ME, Kallen MA, Roundtree AK, Mayes M. Disease and symptom burden in systemic sclerosis: a patient perspective. J Rheumatol 2007; 34(8): 1718-26. [PMID: 17611983]

[30] Knafo R, Haythornthwaite JA, Heinberg L, Wigley FM, Thombs BD. The association of body image dissatisfaction and pain with reduced sexual function in women with systemic sclerosis. Rheumatology (Oxford) 2011; 50(6): 1125-30. [http://dx.doi.org/10.1093/rheumatology/keq443] [PMID: 21278071]

\section{(C) 2017 Csókási et al.}

This is an open access article distributed under the terms of the Creative Commons Attribution 4.0 International Public License (CC-BY 4.0), a copy of which is available at: (https:/creativecommons.org/licenses/by/4.0/legalcode). This license permits unrestricted use, distribution, and reproduction in any medium, provided the original author and source are credited. 